\title{
Identifying Corporate Socially Responsible, Cost Minimizing, Management, and Energy Saving Techniques to be implemented on a University Campus, Through a Paperless Initiative.
}

\author{
Sandra C. Obiora ${ }^{1}$, Olusola O. Bamisile ${ }^{2}$, Kimber Dodge $^{3}$, Mustafa Dagbasi $^{4}$ \\ ${ }^{1}$ Faculty of Management and Economics, University of Electronic Science and Technology of China, Chengdu, \\ Sichuan, P.R.China. \\ ${ }^{2,4}$ Energy Systems Engineering, Cyprus International University, Haspolat-Lefkosa, Via Mersin 10, Turkey \\ ${ }^{3}$ Business Administration Department, Cyprus International University, Haspolat-Lefkosa, Via Mersin 10, \\ Turkey. \\ Corresponding author email: Sandra_ora2000@hotmail.com
}

\begin{abstract}
Due to large consumption and usage of paper in Universities, it is important to find ways to reduce the usage of paper. The aim of the research is to see how going paperless can be achieved by a university environment in Cyprus while at the same time being a profitable decision for the University's management to embark on; one that benefits the society, the environment, and improves the University's image. The goal is to present universities with information on decisions and processes necessary for an organisation to go paperless. Going paperless will create tremendous value for the university's operations. This includes increased recognition and attractiveness, teacher and student productivity, cost reduction, and the creation of environmental friendliness which will lead to an increase in enrollment of new students. This project also highlights various factors regarding going paperless which will provide a brief explanation while addressing the major issues concerning the paperless initiative.
\end{abstract}

Keywords: Corporate social responsibility, Competitive Advantage, Energy conservation, Going Paperless, Key Performance Indicators, Stakeholders

\section{Introduction}

Paper is one of the most important inventions of humankind. Its use is unlimited, and it has its negative consequences. Only each person's efforts can influence in a positive way the solution to this global problem pollution of the Earth's air space. The main raw material for paper is wood pulp. Cellulose is obtained from forest species: mainly of spruce, pine and birch, but also use eucalyptus, poplar, chestnut and other trees. As Conservatree.com cites "Claudia Thompson, in her book Recycled Papers: The Essential Guide (Cambridge, MA: MIT Press, 1992), reports on an estimate calculated by Tom Soder, then a graduate student in the Pulp and Paper Technology Program at the University of Maine (Conservatree.com, 2016). He calculated that, based on a mixture of softwoods and hardwoods 40 feet tall and 6-8 inches in diameter, it would take a rough average of 24 trees to produce a tonne of printing and writing paper, using the Kraft chemical (free sheet) pulping process.

If we assume that the ground wood process is about twice as efficient in using trees, then we can estimate that it takes about 12 trees to make a tonne of ground wood and newsprint. (The number will vary somewhat because there often is more fiber in newsprint than in office paper, and there are several different ways of making this type of paper.)" (Conservatree.com, 2016)

"World consumption of paper has grown 400 percent in the last 40 years. Now nearly 4 billion trees or 35 percent of the total trees cut around the world are used in paper industries on every continent. Today, the world consumes about 300 million tonnes of paper each year. Most of that paper is made from virgin pulp, but recycled paper accounts for 38 percent of the world's total fibre supply and non-wood fibres from plants like hemp or kenaf make up 7 percent. For example, the U.S., which contains only 5 percent of the world's population, uses 30 percent of all paper. In that country, the forest and paper products industry generates $\$ 200$ billion dollars in sales every year, accounting for 7 percent of the total manufacturing output of the United States. About 28 percent of all woodcut in the U.S. is used for papermaking." (Martin, 2011)

To address the problem of overconsumption and wastage of paper that leads to the destruction of trees and polluting the environment, universities have the potential to decrease usage of paper inside the institution.

Throughout the years, universities have turned into visible users of paper. Paper is being used to print out schedules of students every semester, handouts, quizzes, assignments, projects, home works, books, and to record attendance of students. The decreasing amount of paper is only the starting point yet the primary goal is to eliminate the utilisation of paper. Hence, each university will have benefit to expand the efficiency of the 
stakeholders such as lecturers, administration, students and all departments that operate the university at large will decrease the expenses of paper like making copies, printing and storing for the university, and besides, will expand immediate response from the university stakeholders.

Moreover, through this study, it is recognised that going paperless is a dynamic exertion that advances extra time, with the heading towards consuming less paper and making a choice on when to use hardcopy version. Hence it can be inferred that universities can incorporate this project into the core operations of the system and furthermore build the utilisation of online work, for example, online assignments, tests, class participation, e-books and later to incorporate into its different operations.

A paperless work environment is one in which the use of paper is eliminated or greatly reduced. This is done by converting documents and other papers into digital form. This study looks at how a standard university can through "going paperless" save money, boost productivity, save space, make documentation and information sharing easier, keep personal information more secure, and help the environment at the same time. This research has several benefits such as:

- Reduce business cost associated with paper, printers, copiers, fax machines, ink and toner cartridges.

- Eliminate filing cabinets and reduce office space.

- Conduct business in a mobile environment resulting in faster responses to customers.

The objectives proposal approach will be carried on through research by doing survey of which will be carried on through different questionnaires that will be asked to teachers and students

Office spaces in this day and age are more costly today than ever before especially in large cities, and growing economies. Substituting electronic documentation for the existing physical documentation ensures that a substantial amount of office space is saved. The result is that more money is available to invest in core business areas instead of satisfying the repetitive need to supply paper and ink to all operational points. Apart from the cost that will be directly saved from not spending money on paper, printers, and ink, fewer staff members are needed to look after company documents in a paperless system. Operations become faster and more efficient as less office space is required to run the company.

\section{Energy Saving/Green House Gas Emission}

Preventing an energy crisis and also saving energy for future generations is a major goal for energy experts in this 21st century (Devabhaktuni et al, Ali Nezihi Bilge, Ozgur Toy, Mehmet Erdem Gunay, 2015). According to the World Health Organization (WHO) report in 2015, about 250, 000 people die yearly as a result of direct and indirect effects of climate change which is mostly by carbon emission and the rate is expected to double by 2020 (Muneer T, 2006) (WHO, 2015). Reducing the world's carbon emission is one of the core values of UNFCC (United Nations Framework for Climate Change) and KYOTO PROTOCOL and these organisations have helped to reduce the emission of carbon with their various policies to its party members.

When an engineer thinks about access to energy systems or energy generally, whether as an expert for the function of some system or as an energy consumer, a wide range of applications come to mind. Some of these applications include natural gas for industrial use and space heating/space cooling, electricity for electronics or lighting, fossil fuels for transportation and other use. Energy is regarded as an omnipresent commodity in this modern age and both institutions (private corporations, governments, schools, universities etc.) and individuals depend seriously on reliable access to useful energy in all its forms (Vanek, 2012).

Energy system can be looked into as a pyramid in which the first way to save energy is the use of energy conservation followed by energy efficiency and then the use of renewable energy to meet energy demands. These three stages/ranges of the energy system in the pyramid are highly important in the utilization of energy and also in the saving of energy for future generations. These stages are also important in other to have a sustainable environment and also to reduce the climate change or global warming effects. The application of renewable energy is gaining more focus in the world energy market especially in developing countries today with little attention given to energy efficiency and conservation. The need to manage the energy available to us efficiently will be one of the solutions to the world rising demand of energy.

Energy conservation is the reduction in energy consumption by using less energy. The benefit of energy conservation is not only limited to energy saving (Energy Savings from Intelligent Metering and Behavioural Change (INTELLIGENT METERING), July 2009), it also improves environmental quality and sustainability, saves or reduces energy cost, and brings about higher savings of limited non-renewable energy sources etc. Energy conservation is a key to reducing global GHG emission and proper management of energy can bring about huge savings on operating cost organisation (Patrick, 1993).

Trees being the raw material for paper production is a prime absorber of atmospheric $\mathrm{CO} 2$ and can store cab as well. Old trees are less efficient is saving carbon compared to young trees as the absorption rate of a tree decreases as its maturity increases. Although, paper production is not often associated with global warming, in many developed countries, the third or fourth largest source of industrial GHG emissions is the paper 
industry. In U.S. for example, the fourth largest emitter of GHG is the pulp and industry (Impacts on Climate, 2016). In the production of $200 \mathrm{~kg}$ of paper, $160 \mathrm{~kg}$ of $\mathrm{CO} 2$ is emitted to the environment/atmosphere (Paper \& the environment, August 2007). This emission is equivalent the amount of CO2 emitted by a car over a distance of $1,000 \mathrm{~km}$. A decrease of $42 \%$ of $\mathrm{CO} 2$ emission per tonne of paper produced has been recorded by the European paper and pulp industry in the last 25 years.(11) Going paperless is still one of the best ways to reduce the carbon emission by this industry. About 95 million and 20 million of trees are consumed for newsprint and book papers production annually. While $9 \%$ of industrial $\mathrm{CO} 2$ emission is from paper, $26 \%$ of landfills is from paper and its degradation produces methane (a GHG that has a heat trapping capacity 23 times of CO2) ( Impacts on Climate, 2016) (CEPI sustainability report, 2009) .

\section{Metrics}

The main aim of the metrics and the key performance indicators is to show what the project will be concentrating on. To develop its objective of the university going paperless and to help improve the paper recycling process, showing if this a good strategic CSR. Moreover, the metrics is going to show the educational, environmental and economic benefits of going paperless to the University and hopefully help Cyprus as a whole. The project will track the amount of the papers that is currently being used by the university and the increase in the environmental concern over the lack of proper recycling facilities in the country and in the schools. The survey will show how many of the student support the idea of going paperless, that is also we are going to conduct the same survey to show lecturers point of view, help them to shade more light on how effective this can be and how much will they like to use electronic mails and another gadget that help to make their job easy, or to connect with the students.

To go paperless the project evaluates how much the school will benefit from the strategy going forward in the future. The survey result will show the educational advantages of going paperless in that there is always a backup of information, information will never get lost, there is also reduction of important paper loss in offices henceforth meaning that electronically, lectures can now be arranged in order very easily including lecture notes and it also increases the office spaces, sending documents electronically also help student and lecturers in that it increase the participation of the students. The project will track how other universities in North Cyprus are dealing with the problem of paper wastage and how will they feel about going paperless. We will also conduct an extensive research on how other universities around the globe have managed to go green. This project will also track how the government, the communities and the big companies with high paper usage dispose of these papers. Henceforth the survey that was made shows that the government have dumping sites in the mountain and furthermore they pay the South Cyprus for them to recycle their waste, thus one can argue that the government should just use the money they are using to pay the people or companies in the south to establish the recycle center here too, hence this will help the Northern Cyprus society improve waste disposal and efforts towards going green.

\section{Key Performance Indicators}

The major key performances indicator in this project are shown in the survey, a bigger percentage of students agree that going paperless has the potential to make their study life very easy since they can access and write quizzes at home as well as complete other online processes independently. Furthermore, the community is a key performance indicator in that the higher the level of awareness of going paperless, the higher the chance of the community practising it over the long term. This will also force the hand of the government to help the community by improving the recycling process which is not clearly elaborated. The only way that we will know if the project is a success is if the university management body decides to invest in the project of going green that is by showing concern for the amount of paper wastage at the university and furthermore providing extra resources that is needed for the process to work that is the installation of the key cards doors in the classrooms that would allow the lectures to take attendance very effectively. Another way of showing if the project is a success is when the universities also motivates the government of Northern Cyprus to establish recycling plants on the island since according to studies it show that islands have the worst disposal mechanism of the worst hence this clearly shows that the government investments in such a project will help the island to go green and help to reduce the level of pollution, the burning of the waste and reduction of mountain dumping. This can all be a clear indication of the project working thus reduction of dumping areas.

\section{Who needs to be involved and what things must be done}

When considering who needs to be involved, every stakeholder of the university is involved, and will undoubtedly become involved in the process should it be executed. Primarily, the change needs to start from the top. This includes first and foremost getting agreement from the owners and shareholders of the University and then moving on to getting acknowledgement and the full support of the top management which in this case is the rectorate as is required for policy making in the real world. (Michael Hallsworth, 2011) Afterwards, the 
teachers, lecturers, assistants, administrative staff, and students, must be trained and thought about the motives behind going paperless. The advantages of this new system need to be outlined primarily in order to get all the stakeholders on board. The idea needs to be sold to and bought by all these key members otherwise getting it started and implemented will be more stressful and challenging that it should be.

Finances will be required to support the training and awareness process. Through this process, the different stakeholders can gain an understanding of the things to be done and their own contribution to the bigger picture. Proper presentation of this project to the necessary bodies involved is the very first step towards going paperless. Raising awareness of the project and its importance via different means such as survey, social media, interpersonal communications, is the second key step taken towards raising awareness in the minds of key stakeholders on the importance of going paperless.

\section{Communications and marketing strategy}

The aim of the communication and marketing strategy is to reach out to the university and the students concerning the paperless project. In order for this to be a success, we need the lecturers, the Rector, the staff working in the offices and the students all on board. As for the marketing strategy, it is about how we will alert the students and the lecturers on the benefits of going paperless. This will mostly be done through posters, the media and also through the presentation to the Rector and staff.

\section{Internal and External communication}

We must consider that for any venture to be successful we need to communicate it to the target audience. Take a restaurant for instance. If it wishes to get more customers, it needs to get its menu and other competitive advantages out there to its potential customers to know about it. (Obiora, 2016). In the same vein, for a University taking a paperless initiative to become known, it must communicate its actions and choose transparency.

\section{Internal}

Under communication, we have internal and external communication. Internal communication refers mostly to the university staff (the lecturers, those working in the offices). Reaching out to these employees is being done through face to face interviews, online questionnaires, among other things. By so doing; we hope to get their views on what they think about our university implementing the paperless project. Their input is essential as they are affected greatly by this project.

\section{External}

The second aspect of communication is external communication. Here, we are mostly reaching out to the university students whose input is also of great importance. However, we are not just reaching out to the students of one university, but also other students from universities around. By so doing, we are hoping to get information on what their universities are doing or have done to implement the paperless project. We need to know this information so as to present it in our presentation to the university as a way to motivate them and convince them to get on board with the project. The methods used here include the following: face to face interviews, questionnaires and also using media.

\section{Marketing Strategy}

The Marketing strategy deals with how we will advertise the paperless project and help keep the awareness alive. For this, we need posters, the use of social media apps/sites like Facebook, Twitter. Whatsapp and Instagram. The posters must be placed in all blocks of the university on the noticeboard, written in English for international students and also in Turkish. Also, the posters must be placed in other places which are mostly used by the students, like the Cafeteria, dormitories sports arena etc. On top of that, we need to make use of the official university website. Seeing this is where the news about things going in the university is put, it will be ideal to put posts about the paperless project. We can use social media like Facebook by opening a group where posts about the project, sharing different ideas and so on will be done. The questionnaires will also be of great significance here. This will help us have a clear picture of what the students and the lecturers really think about the paperless project.

Finally, there should be a presentation to the school administrators: the Rector and the Staff. It is in this presentation that the school administrators can be convinced that the paperless project is a good investment, one that they should partake in. Diverse and vast marketing strategies should be used to achieve this. By this, the numerous advantages of going paperless are stated, and also show them what the students and the lecturers think about it. 


\section{The Current state of paperless initiatives}

Some universities in North Cyprus that have started abandoning the use of papers and now use technology instead of papers in completing activities that involve formal writings. Interviews carried out from the audiences concerning going paperless, which includes the challenges and the lessons. The paperless initiatives are to support the University by bringing improvement to the environment and also reduce costs by achieving cost savings. With the use of research carried out by other universities such as the Northern Arizona University who have replaced the use of papers, with electronic system that detects each student's ID card when entered through the large doors in the classrooms, and also submission of assignments and reduction of the paper use by buying recycled or thin papers has helped them in achieving their paperless movement goal and reduce costs, and also made a significant reduction in the number of printers supported. (Northern Arizona University, 2016) Cost consideration should be assessed as a process to paperless approach. There will be a slight increase of costs due to purchase and ongoing support for the technology to support electronic document storage.

\section{First steps}

- In order to bring behaviour change, there would be the removal of paper use in the meetings, assignments, attendances, and replacing it with the use of electronic versions such as ID machines detectives, Moodle, recycling of papers, and use of thin papers.

- Provide instructions or handouts to electronic procedures. In order to reduce complication on its use and ensure that the documents are more secure.

\section{Summary of research conducted and benchmarks}

In our instructor interviews, it was evident that they were mostly in support of the idea of going paperless as $87.5 \%$ of the instructors interviewed were in support. While in communication with them, they touched on several key points as regards our project which is to initiate the move towards going paperless. They were of the opinion that instead of spending more time doing things through paper first, it would be easier for them to just check homework, quizzes, and projects through the internet, and in a computerised format from start to finish. Through our research, we came across several students who confirmed that different universities around the world such as Yale University in America, and even Girne American University on this island (Cyprus), participate in paperless practice and we believe most universities has what it takes to accomplish this as well. These universities claim that the reason why they have done this project is basically because it is cheaper for the university, easier, faster and contributes to saving the environment which is in line with their organisational aims, mission, and vision. We however unlike the Yale University are focusing on the SWOT analytical technique to evaluate how universities can go paperless.

Let's examine Yale case going paperless. In FY 2011, the University consumed 211,033 reams of paper, according to the Office of Sustainability - that's enough paper, if laid end to end, to stretch three-quarters of the way around the earth. To look at it another way, some conservation organisations estimate that one ream of paper (500 sheets) uses the equivalent of $6 \%$ of a tree, which would mean Yale used approximately 12,662 trees worth of paper in 2011. The good news is that in FY 2012, paper consumption decreased 2.4 percent to 203,236 reams. However, there is still plenty of work to be done to reach the overall goal of a 25 percent reduction (Ngim, 2016).

See list of Figure I to find Table on Lecturers and Graduate Assistants' survey result

Beyond the toll it takes on our natural resources, there are many other costs associated with a paperbased business culture: printing services, delivery, mailing, storage, processing, disposing, and recycling. Copier and printer supply alone amount to a huge expenditure. Last year, the University spent roughly $\$ 680,000$ on copier paper and twice that amount of toner. Clearly, using less paper is just as much about saving green as being green. Recognising this, Yale departments and schools have taken a variety of steps to save trees and money, many involving digital solutions. For example, the Student Employment office realized annual savings of $\$ 100,000$ by adopting an electronic process to replace paper time sheets, the School of Medicine saved $\$ 92,000$ when the practice of printing paper course packets was replaced with iPads and Finance and Business Operations saved roughly $\$ 60,000$ when it discontinued printing and mailing hard copies of its annual report and instead published it online.

\section{See figure II in list of figures to view Students' survey data results}

At Yale University, the introduction of electronic systems such as these is an effective means of reducing paperwork and streamlining systems, and there are many other projects in the works across campus to eliminate paper-based processes. The introduction of electronic systems such as these is an effective means of reducing paperwork and streamlining systems, and there are many other projects in the works across campus to eliminate paper-based processes. 
While interviewing lecturers about their opinions and views on and what they think, they mentioned that it is a good idea but there will be some advantages and disadvantages of this in the University. One main point made was that it is good because it is faster. Firstly they won't spend more time on papers which they should spend on the computerised and more meaningful work. Also, it is contributing to saving our environment as a planet which is already seeing some of the most obvious signs of reaching some planetary boundaries.

On the other hand, there aren't enough and or lucrative recycling plants on the island of Northern Cyprus. Thus to a large extent, it appears that the wastage of paper is inevitable. Several also explained that basically, it's more difficult for the older staffs to stay in front of the computer for long hours and also the probability of experiencing security issues as a result of completely computerised work is one that needs to be considered and taken seriously.

Regarding some general student responses, one of the Student workers said "It will be a gift for me to do everything online instead of papers" Also he mentioned that going paperless will decrease the cost and save the environment as well. With the saved money, the university can focus even more on stakeholders

According to one of the Campus security officers "it is very good idea and it will have many positive effects on our university and will be helpful for us" but I want to be sure that my works such quizzes, exams, homework's, assignments such like this will be secured and not hacked by someone.

And according to a research assistant in the department of business administration, the usage of paper is actually time wasting, and going paperless will make things faster. He said, "I am the assistant of B.A department and I work with papers a lot, they are my daily activities and it is very difficult to work with papers compared to if most things are done online work will be faster and enjoyable." These are points of some lecturers and an assistant, they tried to mention how this project will be effective and will attain success in the university. They also said if we avoid the disadvantages which were mentioned above and clarify our mission and vision in the project of "going paperless" we can succeed with the project and get an agreement with top management and head of the university.

Some benchmark information

In accordance with our findings, "Girne American University" have been practising online exams and quizzes, we have also come across online software that we can show to our school to help us understand how to implement this idea of online exams and quizzes in all our faculties. According to the primary data, we have collected, it is safe to say that the majority of stakeholders agree and even support the project because going paperless, using e-books instead of hard copy books is more efficient. For the students, it is easy to make the choice for paperless textbooks but some lecturers mentioned that it is not for free, so the amount of money they will charges the students will be included in our annual fees.

\section{Research on how paperless strategies can be implemented}

Concerning the marking of class attendance, because this part of the university system also uses a lot of paper and contributes to resource wastage, we believe it is possible to emulate the same security features already present at some university's dining hall entrance or entrance door to dormitories using student identification card. This is sure to reduce usage of paper and also help prevent all the students from faking signed attendance by letting their friends as we are facing now.

Using recycled papers instead of new ones is also stated in this project. But based on secondary information which we gathered to form the internet, we see that there is nearly no possibility to effectively recycle in Northern Cyprus. There is no solid mechanism or invention in place that lets individual universities fully engage in the process of recycling all form of recyclable goods. We are looking a way to solve this problem in the best way possible. Moreover, we want to mention that if we will reach, this means our university will be the first that did it on this island.

Looking at the responses to the survey which we made via Survey Monkey, we have seen that majority of all the students who responded are in agreement with the idea of going paperless and they support all the points of the project. (See appendices) They also mentioned that it will increase the reputation of the university. It will increase the potential number of students. As we have learned the consumers buys from companies they trust and respect. In this case, students are the consumers. And the project that we are going paperless means trying to improve sustainability of university business and make it more socially responsible among the universities on the island and all of the world

\section{Stakeholder analysis and impact of implementation}

Actually, everyone in any university is related directly to the project. Most importantly, the key stakeholders are the students, teachers, and administrative staff members. When we consider how who all the university stakeholders are. (Wagner 2010) Although the project is bound to have a big impact, we believe it is one that is highly beneficial for everyone. It will directly affect the performance of management, operating employees, security employees, teachers, students and others. Administrative part of the university will perform 
much more effectively and efficiently because of new integrated performance methods which obviously include electronic technology which is faster, mobile, easy to use and take less space in office rather than huge number of physical papers stored in every single cabinet and which have to be transported from point $\mathrm{A}$ to point $\mathrm{B}$ and so on then back to point $\mathrm{A}$.

The education process will be much more productive and comfortable with newly integrated technologies as electronic machines for attendance or new methods of examination as online examinations which will save a lot of time for checking tests and will make examination process much more comfortable for students especially for those who cannot physically attend an exam. Becoming paperless means becoming technologically developed which can also help to become transparent and clear. Transparency will make everyone perform honestly and additionally technology will make communication much easier on all levels beginning from students and ending by the administration and it means that problems and difficulties faced by anyone will reach responsible people as soon as possible and will help management to react on time or even prevent them. Decision becoming paperless can bring unbelievable changes which definitely will be beneficial for every single person who anyhow connected to the university.

Broader Role of CSR in Universities

Becoming a paperless entity can bring about a new state of mind for the students who can become leaders in CSR. Sustainable CSR policy of a University can have a huge and very important role in branding, marketing, advertising and become a tool for attracting new talented people to the citadel of learning. Becoming paperless as was mentioned before cause drastic changes in administration and education process and additionally further development of this topic means recycling paper materials and many other things. These changes and processes can be a base for new researchers especially in administrative sciences and environmental engineering department which can make the organisation one of the leading universities.

As it was described above, going paperless will have a lot of benefits for everyone and now we want to mention some specific parts which could be implemented very easily and in a short period of time. A Huge part of education process takes attendance, assignments, quizzes, home works, exams and textbooks. Let's sort out everything part by part.

\section{The three main phases of the paperless initiative}

As the result of this research, we recommend three main phases. This include:

\section{Part I. Attendance.}

Controlling/taking attendance takes a lot of time, sometimes it causes a mess in class and wastes big amount of paper and time which will not be necessary after just that short period of time. Nowadays many devices could simplify this process and what is very important many of them are for free such as online based attendance checkers. Some apps for Android platform can be downloaded from Google play. Here is few of them: Attendance Manager, Attendance Tracker, and Smart Attendance. If administration of university will not be satisfied by these many types of tools we offer to IT department to create her own simple app where students can "sign" an attendance via their own mobile phones if they know a special code which will be announced during a class, so student will attend a classes to know that code.

\section{Part II. Examination.}

Assignments, quizzes, home works and exams for current situation wastes much more paper than attendance checking and now that number become really huge and additionally that huge amount of paper have to be stored somewhere. If examination will be done online it will simplify a checking and grading process for teachers, it will increase transparency level and very useful for students who can't attend an examination physically because of personal problems and difficulties. The university will have a good base to run "home study" option what will increase the number of students who demands minimum expenses for service. Classic and short answer type examinations can be done online if lecturer wishes to do so. Some teachers may not want to do classic and short answer type examinations online because of the lack of trust to security of software, cheating or just because of their own preferences but as research shows the number of teachers who want to go paperless will palpably decrease the number of used hard papers and it will also decrease amount of expenses for university.

\section{Part III. Textbooks.}

Research show that the path of Going Green already exists and some organisations doing really well. The Florida Polytechnic University has high-tech library which is bookless. Online based libraries will save money and make comfortable education process. Students and teachers will be able to find needed information very fast and from several books at the same time by few keywords. Many high-tech libraries already work as a bookless and have different solutions for implementing this strategy. 


\section{Project overview}

Implementation of the project can be divided into three phases to make it understand and work better:

Phase I - changing the ways of recording attendance and making submissions of home works, assignments and projects online via Moodle. This phase does not require the big amount of investments, will increase productivity, and decrease wastage level.

Phase II - to start using recycled or thinner papers to write quizzes, exams, and some administration work.

Phase III - implementation of e-books into the educational system. This phase requires a large amount of investments but in the long-run perspective, it is very beneficial.

The action plan for the project is:

1. Carrying out primary research.

We are in the process of carrying out a survey for students and lecturers of Cyprus International University.

2. Carrying out secondary research.

- As an alternative for recording attendance on the paper, the university might install the electronic system on the doors of big classrooms. For instance, Northern Arizona University installed an electronic system that detects when each student with an ID card walks through the door to some large classrooms. The system will produce an attendance report for the instructor.

The University is familiar with this electronic system because it has been installed in all dormitories inside the campus. From time to time, it gets more innovative so we assume that using the system to record attendance will not be very costly and time-consuming.

- Home works, assignments, projects should be submitted directly to Moodle. This will significantly reduce the amount of paper being used.

- For quizzes, exams, and for some administration works the university should purchase recycled and/or thinner paper. "Recycling paper conserves natural resources saves energy, reduces greenhouse gas emissions, and keeps landfill space free for other types of trash that cannot be recycled. Recycling one ton of paper can save 17 trees, 7,000 gallons of water, 380 gallons of oil, 3.3 cubic yards of landfill space and 4,000 kilowatts of energy-enough to power the average U.S. home for six months and reduce greenhouse gas emissions by one metric ton of carbon equivalent (MTCE)" (West, 2014). "The thickness of paper being used makes a big difference in terms of both costs as well as the amount of paper used. The reference to the thickness of paper can be found on the package, mostly ranging from $60 \mathrm{gsm}$ or $\mathrm{g} / \mathrm{m} 2$ (grammes per square meter) to $100 \mathrm{gsm}$. Heavier weight sheets use more fibre, cost more per sheet and cost more to post." (Thin Paper Faqs , 2016).

- It is recommended to use SIS system that has been successfully implemented by the University instead of printing out timetables for students;

- Once a year to organise a Paper Free Day. Paper Free Day is an international event, which is aimed at attracting the attention of companies and individuals around the world to modern paperless technology. The campaign encourages learning more, use advanced information, and document management technology to reduce wasteful use of paper.

\section{SWOT analysis on going paperless}

Strengths:

i. The project has been supported by the deputy dean of Faculty of Economics and Administrative Sciences in the university surveyed.

ii. Close to $90 \%$ of the lecturers interviewed are in support of the idea of going paperless. Many even pointed out that it will save them the extra work, and create more work fluidity.

iii. Improvement of financial performance of the university. Using less paper will decrease operation cost.

iv. Enhanced reputation and university image. Implementing strategic CSR will lead to recognition among students and administrative staff. We note that students who in the case of universities count as the customers will be attracted. They will come to experience the uniqueness in person. In essence, as the customers of the university, the University living up to their expectations count as a benefit for all parties. (Hussain B 2005)

v. Sustainable development.

\section{Weaknesses:}

i. No recycling factories.

ii. In the short run, perspective involves financial investment for new technologies.

iii. Lack of information available about utilisation of trash in the Turkish Republic of Northern Cyprus.

iv. Some instructors argued that it is very difficult to be in front of a computer screen much longer than they already are. 
v. Security issues and hacking possibilities when submitting home works, assignments, examinations and projects online.

vi. Uncontrollable wastage of paper.

vii. Low speed of internet or losing internet connection might be a barrier to sending home works, assignments, and projects on time.

\section{Opportunities:}

i. Partnership opportunities in support of university initiatives.

ii. The attraction of bigger amount of students.

iii. The competitive advantage of being one-step ahead of universities in the Turkish Republic of Northern Cyprus.

iv. Development of "Paper Free Day" event. As volunteers, administrative staff and students of universities can plant trees on this day.

v. Contribution towards society. Becoming more environmentally friendly by decreasing pollution through less wastage of paper.

\section{Threats:}

i. The rector and the university board of trustees might not support the idea of going paperless.

ii. Technologies might break down and it will cause a problem.

iii. Some members of administrative staff and students might not stop using less paper.

\section{Successful strategic CSR initiatives.}

"CSR is defined as situations where the firm goes beyond compliance and engages in 'actions that appear to further some social good, beyond the interests of the firm and that which is required by law" (McWilliams, 2006). Although we may not think so often of the global footprint and impacts of universities, as centers for learning, the truth is that universities have to be considered in the fight for achieving a healthier environment. Thus, refusing to eliminate universities from the calculation and obligation of corporate social responsibility is a wise choice. (Mehta, S, R 2011). We can consider that corporate social responsibility is not just for large scale firms. In fact it counts as an important practice for all organizations and firms. (Muhammed B, L 2008). We are focused on supporting the accomplishment of the University's objectives and are completely adjusted to its strategic and academic priorities. The objectives serve as the system by which we work and decide. We achieve needs today without giving up our capacity to meet the natural, economic and societal necessities of the future. Key components of successful strategic CSR initiative includes alignment with core operations of the university as becoming more sustainable developed, strategic alignment through reducing the negative impact on the environment into more competitive and environmentally friendly organisation, attracting more volunteers through enlightening them about global issues of decreasing a number of trees, which counts as ethical and portrays strategic CSR where in the university also benefits greatly. (Muijen H. S. C. A. 2004)

See Figure III to refer to financial approximation

\section{Financial Analysis}

Phase 1.

It's proven that both teachers and students use a great amount of papers on attendance and submissions. Based on the research that we conducted we found out every lecturer has to bring a new attendance sheet for every class that he/she teaches on a daily basis. For example let's assume the same lecturer uses 2 rim paper pack in a month, the cost of 1 rim paper pack is 13TL, therefore the cost of the 2 rim paper packs will be 26TL per month, and 312TL annually per lecturer whereby 6,240TL for 20 lecturers while the total amount used is approximate to be 12,000 papers. These costs can be saved by introducing online attendance where will enhance efficiencies for teachers to do their jobs and also will improve students attendance in class. Moreover, the school should enrich the usage of online platform whereby student's submissions example assignments and projects could be conducted online. Therefore for this phase to be initiated the university will need to invest approximately around 22,500 TL whereby the university will be able to break even within a period of 5 years and have a surplus as shown on the table. These costs include development cost for internal IT, and upgrading costs for school network cause a strong and reliable network will be needed 24/7 for effective usage of online submission and online attendance.

\section{Phase 2.}

The university spends a lot of money and uses a lot of paper in a short period of time, specifically during examinations periods. The university has 4 periods of examinations in a year and yet with each semester 
the teachers do provide quizzes and the amount of papers used is extremely much. The examination periods takes two weeks' time and approximately 25,000 papers are consumed within the 15 faculties and schools whereby it costs the university approximately 39,000TL every year as shown on the table. The university can save these costs by initiating online quizzes and also they could implement the usage of recycled papers specifically for examinations despite the cost to be high for the recycled papers, which will be a disadvantage in a short run, but in the long run the university will be relieved from these costs because they can be reused. Therefore the university will need to invest approximately 108,200TL whereby this money will be allocated in buying the recycled papers, exam/test software, additional hardware like computers will be needed during exams periods, and additional networking costs for the new hardware's added. As shown on the table the university will be able to break even in a period of 5 years and attain a surplus as shown on the table of approximately $11,800 \mathrm{TL}$.

\section{Phase 3.}

The university can save a lot of costs incurred yearly through integrating with online libraries from advanced universities that offer online libraries around the world. The university can use the cost saved from phase 1and phase 2 and use that money to register the university library to online libraries, whereby the university will initially be responsible to register and pay the initial amount for membership and the university will be able to access to the library. Also the university can partner with a reliable online book supplier to provide e-books to the university and also the university can use that money to improve on the university facilities and technologies like WI-FI coverage, increase smart displays in small classes and change damaged projectors for bigger classes.

\section{Conclusion and summary}

All in all the strategic CSR for the university leadership team identified a review of going paperless as an action of learning. The research has shown that paperless is a progressive effort that evolves over time with the direction towards using less paper and making conscious decisions on when to use hardcopy documents. The goal of this project is to initiate the move towards going paperless in a university environment while doing so at a strategic pace. Important steps that need to be taken for this a vast amount of research were outlined. Also benchmarks in and the success stories such as Yale University that exist were reviewed.

The strengths, weaknesses, opportunities and threats involved with the move towards going paperless was used to do the analysis. The views of key stakeholders were identified in form of primary research in the form of online surveys and one on one interviews. The main aim of this project is to present strategic CSR with information that aids informed decision making and favourable approaches towards change in universities as regards going paperless. Furthermore, the cost implication and the supporting technology needs were examined. The present state of paperless initiatives within and outside of the university and relatively easy and low-cost opportunities towards a paperless office was presented.

Some necessary decision pathways for the short term.

Phase 1: Attendance and submissions

Step 1: Eliminate paper usage in all forms of submissions.

Step 2: Eliminate paper usage as regards course registrations, and replication of student's information.

Step 3: Enhancement of the university website to accommodate online attendance taking, and precision.

Phase 2: Tests and quizzes

Step 1: Investment in exam taking software.

Step 2: Improve and solidify network technology and IT available to the university to work effectively during exams.

\section{Phase 3: E-textbooks and other initiatives}

Step 1: Investment in partnership with E-textbook providers like Amazon to reduce usage of paperback textbooks.

Step 2: Create a recycling business on the island.

Step 3: investment in the thin or recycled paper.

Step 4: Make mandatory print outs double sided printing.

Step 5: Investment in the training program to raise awareness, and connect stakeholders to the paperless initiative.

A university system moving to paperless processes will remain a step by step change. Each process will result in improving and enhancing the process via which things are done also possible cost reductions in terms of operations. Also, the move towards going paperless is one that speaks volume not just in the economic sense for the university, but also in terms of enhancing its public image, reputation, and relationship with all of its current and potential stakeholders. 
Identifying Corporate Socially Responsible, Cost Minimizing, Management, and Energy Saving ..

\section{Next steps}

- To update and enhance the finances in all details necessary

- Consider which projects are already under implementation

- Strategize the execution of the segments not yet under implementation.

- Consideration of all other cost cutting and efficiency mechanisms

- Marketing and communication

- Change management involved in implementing project paperless effectively

- Execution of a pilot using the faculty of Economics and Administrative Sciences as the case study.

- All other follow-up support required of us as pioneers and stewards of project paperless in the future.

[1]. CEPI sustainability report (2009).

\section{References}

[2]. Conservatree.com. (n.d.). How Much Paper Can Be Made from a Tree? Retrieved April 24, 2016, from Conservatree: http://conservatree.org/learn/EnviroIssues/TreeStats.shtml

[3]. Devabhaktuni et al, Ali Nezihi Bilge, Ozgur Toy, Mehmet Erdem Gunay. (2015). Business \& Economics

[4]. Energy Savings from Intelligent Metering and Behavioural Change (INTELLIGENT METERING), . (July 2009). Retrieved from European Commission's Directorate-General for Energy and Transport initiative.

[5]. Hussain B., and M. Hussain (2005), “Corporate Social Responsibility: Do Customers Get What They Expect?” Journal of Business Studies, Southeast University, ISSN- 1815- 3267 Vol 1 No. 1, July-December, pp 133 - 139.

[6]. Impacts on Climate. ( 2016). Retrieved from The Green Press Initiative: http://www.greenpressinitiative org/impacts/climateimpacts.htm

[7]. Martin, S. (2011, September 10). Paper Chase| Ecology Global Network. Retrieved from Ecology Global Network. N.p.: http://www.ecology.com/2011/09/10/paper-chase/

[8]. McWilliams, A. D. (2006, January 10). Corporate Social Responsibility. Strategic Implications , 1-18.

[9]. Mehta S, R (2011, November) Corporate Social Responsibility (CSR) and Universities: Towards an Integrative Approach Vol. 1 No 4 (1) $1-5$

[10]. Michael Hallsworth, Policy Making in the real world, 2011

[11]. Muhammed B, L (2008, January) Three Dimensional Aspects of Corporate Social Responsibility. Daffodil International University journal of Business and Economics Vol. 3 no 1, (1) 1-14

[12]. Muijen H. S. C. A. (2004) “Corporate Social Responsibility Starts at University,” Journal Of Business Ethics, vol. 53, numbers 1-2, pp. 235-246,

[13]. Muneer T, M. S. ( 2006). Prospects of solar water heating for textile industry in Pakistan. Renewable and Sustainable Energy Reviews, 10(1), 1-23.

[14]. Ngim, R. (2016, March 31). Yale Going Paperless to Save Money, Time, and Trees. Retrieved from Yale Going Paperless to Save Money, Time, and Trees: http://its.yale.edu/news/yale-going-paperless-save-money-time-and-trees

[15]. Northern Arizona University. (2016, April 1). Retrieved from Office of Sustainability: https://nau.edu/green-nau/office-ofsustainability/

[16]. (August 2007). Paper \& the environment. ATS consulting Myths and Realities brochure.

[17]. Obiora, C, S (2016). 'Differentiation Techniques and Competitive advantage for an African restaurant operating in an international.' Journal of International Review of Management and Business Research June 2016 issue, pg 453

[18]. Patrick, S. R. (1993). Energy Conservation Guidebook. Retrieved from https://books.google.com.cy/books?id=f45IIzt4DCIC\&

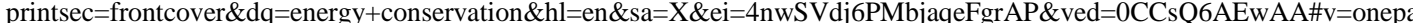

[19]. Thin Paper Faqs . (2016, April 10). Retrieved from Bollorethinpapers.com: http://www.bollorethinpapers.com/en/why-thinpaper/thin-paper-faqs

[20]. Vanek, F. M. (2012). Energy Systems Engineering Evaluation and Implementation. doi:SBN 978-0-07-149593-6

[21]. West, L. (2014). "What Are the Benefits of Recycling Paper? Retrieved from http://environment.about.com/od/recycling/a/TheBenefits-Of-Paper-Recycling-Why-Recycle-Paper.htm

[22]. WHO. (2015). World Health Organization . Retrieved March 2016, from http://www.who.int/mediacentre/news/statements /2015/climate-change/en/

\section{List of Tables and Figures}

Figure I: Lecturers and Graduate assistants survey results

\begin{tabular}{|l|l|l|l|l|l|}
\hline Question & Strongly Agree & Agree & Disagree & Strongly disagree & Total \\
\hline My university uses too much paper & $25.00 \%$ & $62.50 \%$ & $12.50 \%$ & $0 \%$ & $100 \%$ \\
\hline My university has what it takes to go paperless & $12.50 \%$ & $75.00 \%$ & $12.50 \%$ & $0 \%$ & $100 \%$ \\
\hline $\begin{array}{l}\text { I prefer computerized work to working with } \\
\text { printed out paper }\end{array}$ & $37.50 \%$ & $62.50 \%$ & $0 \%$ & $0 \%$ & $100 \%$ \\
\hline $\begin{array}{l}\text { I am willing to receive all my students assignment } \\
\text { submissions online }\end{array}$ & $25.00 \%$ & $62.50 \%$ & $0 \%$ & $12.50 \%$ & $100 \%$ \\
\hline $\begin{array}{l}\text { I am in support of my university eliminating paper } \\
\text { from its systems }\end{array}$ & $37.50 \%$ & $50.00 \%$ & $12.50 \%$ & $0 \%$ & $100 \%$ \\
\hline $\begin{array}{l}\text { I am willing to have my students sign into their } \\
\text { class attendance online or by a paperless means }\end{array}$ & $50.00 \%$ & $12.50 \%$ & $12.50 \%$ & $25 \%$ & $100 \%$ \\
\hline $\begin{array}{l}\text { I will prefer to have my students write their } \\
\text { quizzes and exams online }\end{array}$ & $12.50 \%$ & $37.50 \%$ & $25.00 \%$ & $25.00 \%$ \\
\hline $\begin{array}{l}\text { I am willing to use recycled paper instead of new } \\
\text { paper for exams and all processes }\end{array}$ & $75.00 \%$ & $25.00 \%$ & $0 \%$ & $0 \%$ & $100 \%$ \\
\hline $\begin{array}{l}\text { I will prefer to use E-book textbooks instead of } \\
\text { printed out books for my courses }\end{array}$ & $25.00 \%$ & $62.50 \%$ & $12.50 \%$ & $0 \%$ \\
\hline
\end{tabular}


Identifying Corporate Socially Responsible, Cost Minimizing, Management, and Energy Saving ..

Figure II: Table 1: Students' survey data results

\begin{tabular}{|c|c|c|c|c|c|}
\hline Question & $\begin{array}{l}\text { Strongly } \\
\text { Agree }\end{array}$ & Agree & Disagree & $\begin{array}{l}\text { Strongly } \\
\text { disagree }\end{array}$ & Total \\
\hline This university can go paperless & $27.86 \%$ & $40.16 \%$ & $27.04 \%$ & $4.91 \%$ & $100 \%$ \\
\hline I am willing to write my quizzes and some exams online & $49.10 \%$ & $19.60 \%$ & $27.00 \%$ & $4.00 \%$ & $100 \%$ \\
\hline $\begin{array}{l}\text { I am willing to use recycled paper instead of new paper } \\
\text { for exams }\end{array}$ & $35.20 \%$ & $34.40 \%$ & $21.60 \%$ & $8.80 \%$ & $100 \%$ \\
\hline $\begin{array}{l}\text { I would prefer to use an e-book than a paperback } \\
\text { textbooks for my courses each semester }\end{array}$ & $53.65 \%$ & $28.45 \%$ & $13.00 \%$ & $4.00 \%$ & $100 \%$ \\
\hline $\begin{array}{l}\text { going paperless will improve the image and reputation } \\
\text { of the University }\end{array}$ & $53.33 \%$ & $29.03 \%$ & $18.54 \%$ & $0.01 \%$ & $100 \%$ \\
\hline
\end{tabular}

Figure III Financial analysis approximate breakdown in Turkish Liras.

\begin{tabular}{|c|c|c|c|c|c|c|c|c|}
\hline & & & Year 0 & Year 1 & Year 2 & Year 3 & Year 4 & Year 5 \\
\hline \multicolumn{9}{|l|}{ Phase 1} \\
\hline & Costs & & & & & & & \\
\hline & & Paper & 6240 & 6,240 & $-6,240$ & $-6,240$ & $-6,240$ & $-6,240$ \\
\hline & & Developmen & & 2,500 & & & & \\
\hline & & Network & & 20,000 & & & & \\
\hline & & Hardware & & - & & & & \\
\hline & & & & 16,260 & 10,020 & 3,780 & $-2,460$ & $-8,700$ \\
\hline \multicolumn{9}{|l|}{ Phase 2} \\
\hline & & Paper & 39000 & $-30,000$ & $-30,000$ & $-30,000$ & $-30,000$ & $-30,000$ \\
\hline & & \multicolumn{2}{|c|}{ Recycled Paper } & 18,200 & & & & \\
\hline & & \multicolumn{2}{|c|}{ Exam/Test Software } & 50,000 & & & & \\
\hline & & \multicolumn{2}{|c|}{ Additional Hardware } & 50,000 & & & & \\
\hline & & \multicolumn{2}{|c|}{ Additional Networking } & 20,000 & & & & \\
\hline & & & & 108,200 & 78,200 & 48,200 & 18,200 & $-11,800$ \\
\hline
\end{tabular}

\section{Acknowledgement}

I would like to recognize the following people for their contributions towards making this project and paper a success. Aliya Nurgozhinova, Sarah Richard Kigaraba, Hemed Hamidu, Darryl Maruziva, Salome Solomon, Akzhan Adilkhanova, Manucher Ganiev, Hidayet Abbasov, Campbell Eluonye Agoh, Emin Bayyayev, Ndabezinhle Adrian Msimanga, Edwin Gabriel Kalinga. 